\title{
Perineural Invasion Absent
}

National Cancer Institute

\section{Source}

National Cancer Institute. Perineural Invasion Absent. NCI Thesaurus. Code C160831.

An indication that perineural invasion is absent. 